\title{
Ethyl Cellulose Microparticles Containing Metformin HCl by Emulsification-Solvent Evaporation Technique: Effect of Formulation Variables
}

\author{
Ruma Maji, ${ }^{1}$ Somasree Ray, ${ }^{2}$ Biswarup Das, ${ }^{1}$ and Amit Kumar Nayak ${ }^{1}$ \\ ${ }^{1}$ Department of Pharmaceutics, Seemanta Institute of Pharmaceutical Sciences, Jharpokharia, Mayurbhanj 757086, India \\ ${ }^{2}$ Department of Pharmaceutics, Gupta College of Technological Sciences, Asansol 713301, India
}

Correspondence should be addressed to Ruma Maji, ruma.maji@rediffmail.com

Received 7 January 2012; Accepted 29 January 2012

Academic Editors: I. Cheong and F. Fraga López

Copyright (C) 2012 Ruma Maji et al. This is an open access article distributed under the Creative Commons Attribution License, which permits unrestricted use, distribution, and reproduction in any medium, provided the original work is properly cited.

\begin{abstract}
The work investigates the effect of various formulation variables like drug-polymer ratio, stirring speed, and surfactant (Span 80) concentration on the properties of ethyl cellulose microparticles containing metformin $\mathrm{HCl}$, prepared by emulsification solvent evaporation technique. The drug entrapment efficiency, particle size, and drug release behaviour of these microparticles were influenced by these formulation variables. The sustained release characteristic of these microparticles was more prominent in $\mathrm{pH}$ 6.8 than $\mathrm{pH}$ 1.2. The drug release from ethyl cellulose microparticles was found to follow the Fickian (diffusion-controlled) release mechanism. The drug-polymer interaction and surface topography of these microparticles were analyzed by FTIR spectroscopy and SEM, respectively.
\end{abstract}

\section{Introduction}

Metformin $\mathrm{HCl}$ is a biguanide antihyperglycemic drug, which is orally used in the management of noninsulin-dependent diabetes mellitus (NIDDM or Type II diabetes mellitus) alone or in combination with other hypoglycemics $[1,2]$. Its antihyperglycemic effect is due to the metabolic activities at several sites (biophase), including liver, intestinal muscle cells, and adipocytes [3]. Metformin also has beneficial effect on several cardiovascular risk factors such as dyslipidemia, elevated plasma-plasminogen activator inhibitor, other fibrinolytic abnormalities and insulin resistance [4]. It has a short biological half-life of $1.5-1.6 \mathrm{~h}$ and the daily requirement of it is $1.5-3 \mathrm{~g} /$ day $[5,6]$. Therefore, the marketed immediate release product needs to be administered 23 times daily to maintain effective plasma concentration [7]. Henceforth, there being high incidence of gastrointestinal side effects and toxicity. These drawbacks can be overcome by designing suitable sustained release metformin $\mathrm{HCl}$ formulations. Administration of a sustained metformin $\mathrm{HCl}$ release dosage form could reduce the dosing frequency and improve the patient compliance.
Among various oral sustained drug delivery systems, polymeric microparticles are one of the options and have been studied in past few decades in order to deliver drug molecules to the target site with specificity with several advantages like better oral bioavailability of drugs, reduction in side effects, decreased dosing frequency, and hence, improved patient compliance [8-10]. Microparticles are solid particles ranging in size from 1 to $1000 \mu \mathrm{m}$. In general, polymeric microparticles consist of polymeric matrix, in which drug molecules are dispersed, entrapped, or adsorbed. A number of different polymers both biodegradable and nonbiodegradable have been investigated for preparation of polymeric microparticles [11]. Among them, ethyl cellulose is a water insoluble, nonbiodegradable, biocompatible, and nontoxic cellulose polymer, widely used in formulation of pharmaceutical products $[12,13]$. It is also studied extensively as encapsulating material for sustained release of various drugs [13-15]. However, a few works have been carried out so far to prepare metformin $\mathrm{HCl}$ loaded ethyl cellulose microparticulate systems. Kar and Choudhury have formulated ethyl cellulose microspheres of metformin $\mathrm{HCl}$ by the double emulsion-solvent diffusion method, 
where a mixed solvent system consisting of acetonitrile, dichloromethane, and liquid paraffin were used as solvents [16]. The surfactant, Span 80 was used here for stabilizing the secondary oil phase. In another investigation, the same research group has prepared ethyl cellulose microspheres containing metformin $\mathrm{HCl}$ varying drug-polymer ratios by different microencapsulation techniques, where Span 80 was used during emulsification and petroleum ether was used in nonsolvent addition process [17]. Patel et al. have also developed floating ethyl cellulose microspheres of metformin $\mathrm{HCl}$ by nonaqueous emulsification-solvent evaporation technique, where acetone and liquid paraffin were used as solvents [18].

In the present investigation, we made an attempt to prepare various ethyl cellulose microparticles of metformin $\mathrm{HCl}$ by emulsification-solvent evaporation technique varying various formulation variables like drug-polymer ratio, stirring speed, and surfactant (Span 80) concentration where methanol, acetone, and liquid paraffin were used as solvents. The effect of above-mentioned formulation variables on the drug entrapment efficiency, particle size, and drug release behaviour of ethyl cellulose microparticles of metformin $\mathrm{HCl}$ were investigated.

\section{Materials and Methods}

2.1. Materials. Metformin $\mathrm{HCl}$ was a gift sample from Abhilash Chemicals Pvt. Ltd., India. Ethyl cellulose (18-22 cps, Loba Chemie Pvt. Ltd., India), Span 80 (Ranbaxy Fine Chemicals Ltd., India), methanol (International Chemicals, India), acetone (Merck Specialities Pvt. Ltd., India), liquid paraffin (Merck Specialities Pvt. Ltd., India), petroleum ether (Merck Specialities Pvt. Ltd., India), potassium dihydrogen orthophosphate (Qualigens Fine Chemicals, India), sodium hydroxide pellets (Qualigens Fine Chemicals, India), and hydrochloric acid (Qualigens Fine Chemicals, India) were used. All other chemicals were of analytical grade and were used as procured.

\subsection{Preparation of Ethyl Cellulose Microparticles Containing} Metformin $\mathrm{HCl}$. Ethyl cellulose microparticles containing metformin $\mathrm{HCl}$ were prepared by emulsification solvent evaporation technique varying various formulation variables. Briefly, the drug, metformin $\mathrm{HCl}$ was mixed in methanol and ethyl cellulose was mixed in acetone at various drug-polymer ratios $(1: 2,1: 4$, and $1: 6)$. Then, these two were mixed properly, and the slurry was slowly introduced into $50 \mathrm{~mL}$ of liquid paraffin containing Span $80(2 \%$, $4 \%$, and $6 \%, \mathrm{v} / \mathrm{v})$, as stabilizer and stirred $(400,600$, and $1000 \mathrm{rpm}$ ) by a mechanical stirrer equipped with a three bladed propeller (Bio Lab Instruments, Type-BL233, India) at room temperature for $2 \mathrm{~h}$ to allow the solvent to evaporate completely, and the formed microparticles were collected by filtration. The microparticles were washed repeatedly with petroleum ether $\left(40^{\circ}-60^{\circ} \mathrm{C}\right)$ until free from oil. The collected microparticles were dried for $1 \mathrm{~h}$ at room temperature and subsequently stored in a desiccator over fused calcium chloride. Different formulae of ethyl cellulose microparticles
TABLE 1: Formula of ethyl cellulose microparticles containing metformin $\mathrm{HCl}$ prepared by emulsification-solvent evaporation technique using various formulation variable settings.

\begin{tabular}{lccc}
\hline $\begin{array}{l}\text { Formulation } \\
\text { codes }\end{array}$ & Drug: Polymer & $\begin{array}{c}\text { Stirring } \\
\text { speed (rpm) }\end{array}$ & $\begin{array}{c}\text { Surfactant (Span } \\
80) \\
\text { concentration } \\
(\%, \mathrm{v} / \mathrm{v})\end{array}$ \\
\hline F1 & $1: 2$ & 800 & 4 \\
F2 & $1: 4$ & 800 & 4 \\
F3 & $1: 6$ & 800 & 4 \\
F4 & $1: 6$ & 400 & 4 \\
F5 & $1: 6$ & 600 & 4 \\
F6 & $1: 6$ & 1000 & 4 \\
F7 & $1: 6$ & 400 & 2 \\
F8 & $1: 6$ & 400 & 6 \\
\hline
\end{tabular}

containing metformin $\mathrm{HCl}$ with their experimental formulation variables settings are presented in Table 1.

2.3. Determination of Drug Entrapment Efficiency. $20 \mathrm{mg}$ of microparticles were taken in $250 \mathrm{~mL}$ volumetric flask, and the volume was made up to $250 \mathrm{~mL}$ by phosphate buffer, $\mathrm{pH}$ 6.8. The whole system was kept for $24 \mathrm{~h}$. Then the solution was filtered, and estimated for metformin $\mathrm{HCl}$ content spectrophotometrically at $233 \mathrm{~nm}$ against appropriate blank. The drug entrapment efficiency (\%) of these microparticles was calculated by the following formula:

$$
\begin{aligned}
& \text { Drug entrapment efficiency, \% } \\
& \qquad=\left[\frac{\text { Actual drug load }}{\text { Theoretical drug load }}\right] \times 100
\end{aligned}
$$

2.4. Fourier Transform Infrared (FTIR) Spectroscopy. FTIR spectra of pure drug (metformin $\mathrm{HCl}$ ), ethyl cellulose, blank ethyl cellulose microparticles, and drug loaded ethyl cellulose microparticles were obtained by an FTIR spectroscope (Perkin Elmer Spectrum RX I, USA) using KBr disc method. Samples were gently triturated with $\mathrm{KBr}$ powder in a weight ratio of $1: 100$ and then pressed using a hydraulic press at a pressure of 100 tons for 10 minutes to prepare KBr pellets. These discs were placed in the sample holder and scanned between $4000 \mathrm{~cm}^{-1}$ to $450 \mathrm{~cm}^{-1}$ at a resolution of $4 \mathrm{~cm}^{-1}$.

2.5. Particle Size Measurement. Microparticles were separated into different size fraction by sieving for 10 minutes using a mechanical shaker (Geologists Syndicate Pvt. Ltd., India) containing standard sieves having aperture of 1400, $1000,355,250,180,150,125$, and $63 \mu \mathrm{m}$. The mean particle size of microparticles was calculated.

2.6. Surface Topography Analysis. The surface topography of microparticles was examined by scanning electron microscopy (SEM). The samples for the SEM analysis were prepared by sprinkling the microparticles on the side of the double adhesive stub. The stub was then coated with gold, 
and gold-coated samples were observed by scanning electron microscope (JEOL, JSM-5200, Japan).

2.7. In Vitro Drug Release Study. In vitro drug release studies were carried out at $37 \pm 1^{\circ} \mathrm{C}$ and $50 \mathrm{rpm}$ using $0.1 \mathrm{~N}$ $\mathrm{HCl}, \mathrm{pH} 1.2$ for $2 \mathrm{~h}(900 \mathrm{~mL})$, and phosphate buffer, $\mathrm{pH} 6.8$ for $6 \mathrm{~h}(900 \mathrm{~mL})$, for all products in USP type II dissolution apparatus (Campbell Electronics, Mumbai). Accurately weighed samples of microparticles were added to dissolution mediums. $10 \mathrm{~mL}$ of aliquots was collected at regular time intervals, and the same amount of fresh dissolution medium was replaced into dissolution vessel to maintain the sink condition throughout the experiment. The collected aliquots were filtered and suitably diluted to determine the absorbance using a UV-VIS spectrophotometer (Shimadzu, Japan) at $233 \mathrm{~nm}$ for phosphate buffer, $\mathrm{pH} 6.8$ and $206 \mathrm{~nm}$ for $0.1 \mathrm{~N} \mathrm{HCl}, \mathrm{pH} 1.2$.

2.8. Kinetics of Drug Release. Release of drug molecules from a simple swellable polymeric matrix can be described by the following power law expression:

$$
\frac{M_{t}}{M_{\infty}}=k t^{n},
$$

where $M_{t}$ and $M_{\infty}$ are, respectively, the amount of drug released at time, $t$, and at infinite time, $k$ represents a rate constant, and $n$ is the diffusional exponent; this indicates the drug release mechanism [19]. To evaluate the mechanism of drug release from different ethyl cellulose microparticles containing metformin $\mathrm{HCl}$, the drug release data for $6 \mathrm{~h}$ were fitted in the logarithmic form of the power law equation:

$$
\log \left[\frac{M_{t}}{M_{\infty}}\right]=\log k+n \log t
$$

The values of $n$ were determined from the slops and intercepts of the straight line. In case of Fickian release (diffusion-controlled release) from spherical matrices, the value of $n$ is $\leq 0.43$, whereas in case of case-II transport (relaxation-controlled release), it is $\geq 0.85$. The non-Fickian release (anomalous transport) of drugs occurs when the values of $n$ fall within 0.43 and $0.85[20,21]$.

2.9. Statistical Analysis. The data were expressed as mean \pm standard deviation (S.D.), $n=3$. The significance of the drug release results was assessed by one-way analysis of variance (ANOVA). A $P$ value of $<0.05$ was considered significant.

\section{Results and Discussion}

Metformin $\mathrm{HCl}$ loaded ethyl cellulose microparticles were prepared by emulsification-solvent evaporation technique. The effects of various formulation variables like drug-polymer ratio, stirring speed, and surfactant (Span 80) concentration on the microparticle characteristics (drug entrapment efficiency, particle size, and drug release behaviour) were investigated.
TABLE 2: Drug entrapment efficiency (\%) and mean particle size of ethyl cellulose microparticles containing metformin $\mathrm{HCl}$.

\begin{tabular}{lcc}
\hline $\begin{array}{l}\text { Formulation } \\
\text { codes }\end{array}$ & $\begin{array}{c}\text { Drug entrapment } \\
\text { efficiency }(\%)^{\$}\end{array}$ & Mean particle size $(\mu \mathrm{m})^{\$}$ \\
\hline F1 & $45.66 \pm 1.53$ & $145.89 \pm 18.95$ \\
F2 & $65.13 \pm 1.99$ & $195.53 \pm 37.32$ \\
F3 & $66.67 \pm 1.41$ & $373.60 \pm 23.52$ \\
F4 & $69.34 \pm 0.93$ & $845.92 \pm 29.30$ \\
F5 & $67.63 \pm 2.40$ & $223.86 \pm 37.18$ \\
F6 & $62.49 \pm 1.16$ & $134.44 \pm 19.05$ \\
F7 & $74.95 \pm 2.65$ & $954.47 \pm 11.58$ \\
F8 & $70.48 \pm 1.62$ & $241.65 \pm 28.33$ \\
\hline
\end{tabular}

${ }^{s}$ All data were expressed as mean \pm S.D., $n=3$.

3.1. Drug Entrapment Efficiency. The drug entrapment efficiency (\%) of various formulated ethyl cellulose microparticles containing metformin $\mathrm{HCl}$ was within the range of $45.66 \pm 1.53$ (F1) to $74.95 \pm 2.65 \%$ (F7) (Table 2). A significant increase in drug entrapment efficiency (\%) of these microparticles $(P<0.05)$ was observed with the decreasing drug-polymer ratio (increasing polymer content), when stirring speed and surfactant concentration were constant. The higher the polymer content, the higher the probability of drug surrounded by the polymer, which acted as barrier to prevent diffusion of drug molecules into the external phase. But no significant differences $(P>0.05)$ were observed with the variation of stirring speed (400 to $100 \mathrm{rpm}$ ) and surfactant (Span 80) concentration (2 to 6\%, $\mathrm{v} / \mathrm{v}$ ), when other formulation variables were constant.

3.2. Particle Size. The mean particle size of ethyl cellulose microparticles containing metformin $\mathrm{HCl}$ are presented in Table 2, and all these microparticles were within the range of $134.44 \pm 19.05$ to $954.47 \pm 11.58 \mu \mathrm{m}$. Decreasing the drug-polymer ratio from $1: 2$ to $1: 6$ (increasing the ethyl cellulose content) in the preparation of these ethyl cellulose microparticles resulted in the formation of comparatively larger microparticles $(145.89 \pm 18.95$ to $373.60 \pm 23.52 \mu \mathrm{m})$. This observation may be attributed to an increase in viscosity of the internal phase with the increasing amount of polymer, ethyl cellulose. The higher the viscosity of the internal phase, the greater the amount of energy required to break the drug-polymer droplets into smaller particles [22]. On the other hand, with the increasing of stirring speed from 400 to $800 \mathrm{rpm}$, the mean particle size of these microparticles was decreased from $845.92 \pm 29.30$ to $134.44 \pm 19.05 \mu \mathrm{m}$. This phenomenon strongly supports the idea that the high stirring speed could provide high shearing force needed to breakdown the drug-polymer droplets into smaller particles $[22,23]$. Again, as the concentration of surfactants, Span 80 was increased from 2 to $6 \% \mathrm{v} / \mathrm{v}$; the mean particle size of these microparticles was reduced from $954.47 \pm$ 11.58 to $241.65 \pm 28.33 \mu \mathrm{m}$. This was in accordance with the theory of effect of surfactant concentration on particle size. 


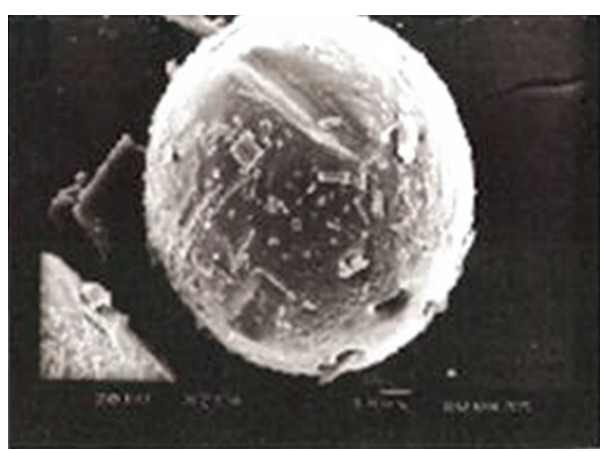

(a)

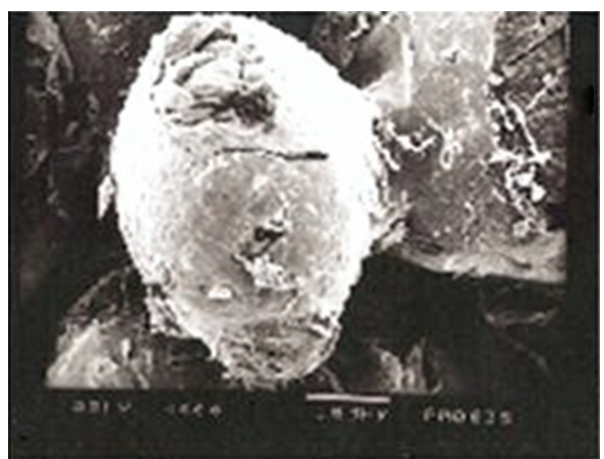

(c)

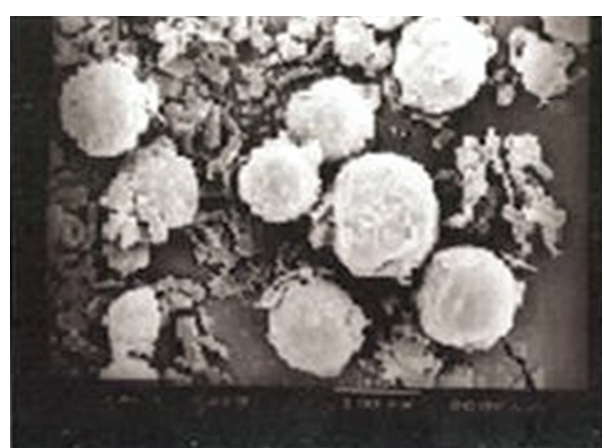

(b)

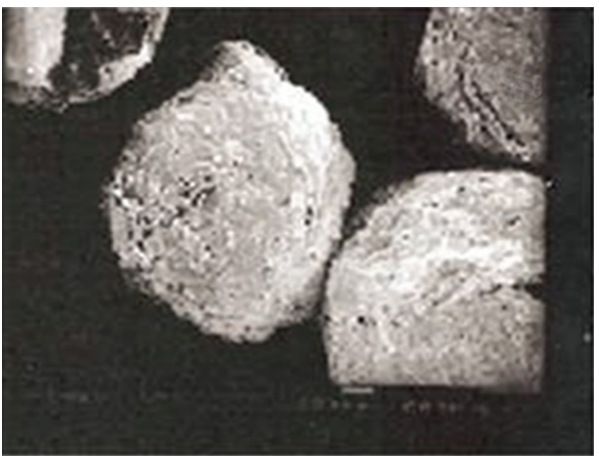

(d)

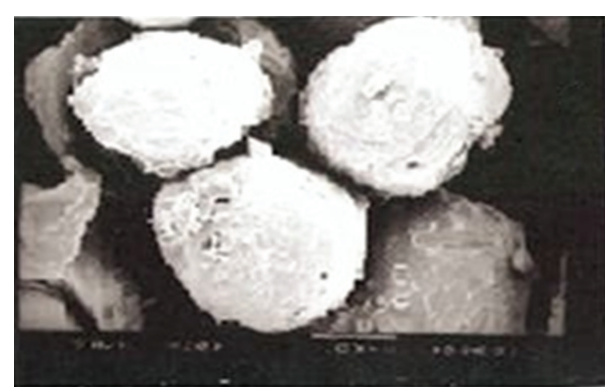

(e)

FIGURE 1: Scanning electron micrographs of various ethyl cellulose microparticles containing metformin HCl: F1 (a), F3 (b), F4 (c), F5 (d), and F7 (e).

3.3. Surface Topography. The surface morphology of ethyl cellulose microparticles containing metformin $\mathrm{HCl}$ was analyzed by SEM (JEOL, JSM-5200, Japan). The SEM photographs of various microparticles are presented in Figure 1. The surface of these microparticles was rough and revealed the presence of pores in the drug-loaded microparticles. Again, the SEM photograph of drug-loaded microparticles showed the presence of drug particles on their surface, which was responsible for the initial burst release of drug during dissolution [24].

3.4. FTIR Spectroscopy. The FTIR spectra (Figure 2) revealed that there was no such interaction between metformin $\mathrm{HCl}$ and the polymer, ethyl cellulose. The principal absorption peaks of metformin $\mathrm{HCl}$ appear at $3169 \mathrm{~cm}^{-1}$ due to the $\mathrm{N}-\mathrm{H}$ stretching of the primary amine group $\left(-\mathrm{NH}_{2}\right)$ and at $1063 \mathrm{~cm}^{-1}$ due to $\mathrm{C}-\mathrm{N}$ stretching. A peak at $1584 \mathrm{~cm}^{-1}$ occurs due to $\mathrm{N}-\mathrm{H}$ bending vibrations of the primary amine group. The identical peaks (N-H stretching, C-N stretching, and $\mathrm{N}-\mathrm{H}$ bending vibrations) were also appeared in the spectra of ethyl cellulose microparticles containing metformin $\mathrm{HCl}$. However, these were absent in blank ethyl cellulose microparticles.

3.5. In Vitro Drug Release. The percentage of drug (metformin $\mathrm{HCl}$ ) released from ethyl cellulose microparticles were evaluated in $0.1 \mathrm{~N} \mathrm{HCl}, \mathrm{pH} 1.2$ and phosphate buffer, $\mathrm{pH}$ 6.8. The sustained release characteristic of these microparticles was more prominent in $\mathrm{pH} 6.8$ than $\mathrm{pH}$ 1.2. The release of metformin $\mathrm{HCl}$ from formulation of F3, F4, and F7 was slower than other formulations. The in vitro release of metformin $\mathrm{HCl}$ from ethyl cellulose microparticles was biphasic with the initial burst drug release effect, which was varied depending on the drug-polymer ratio. The initial burst effect may be attributed as a desired effect to ensure initial high plasma concentration of drug to 


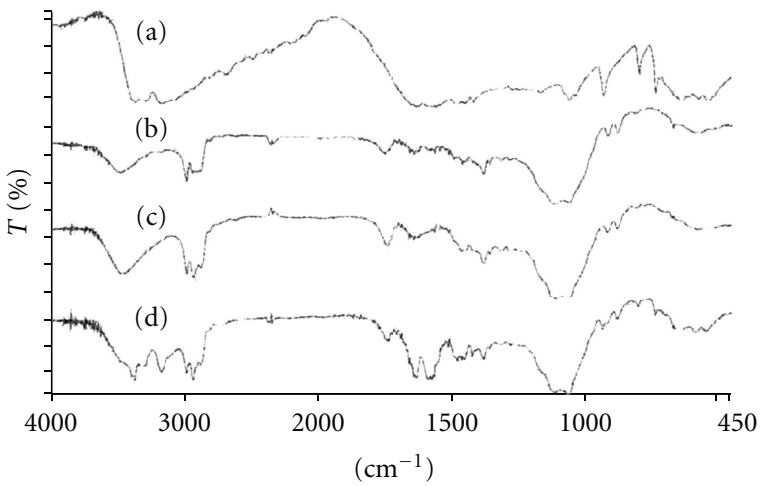

FIGURE 2: FTIR spectrum of metformin $\mathrm{HCl}$ (a), ethyl cellulose (b), blank ethyl cellulose microparticles (c) and metformin $\mathrm{HCl}$ loaded ethyl cellulose microparticles (d).

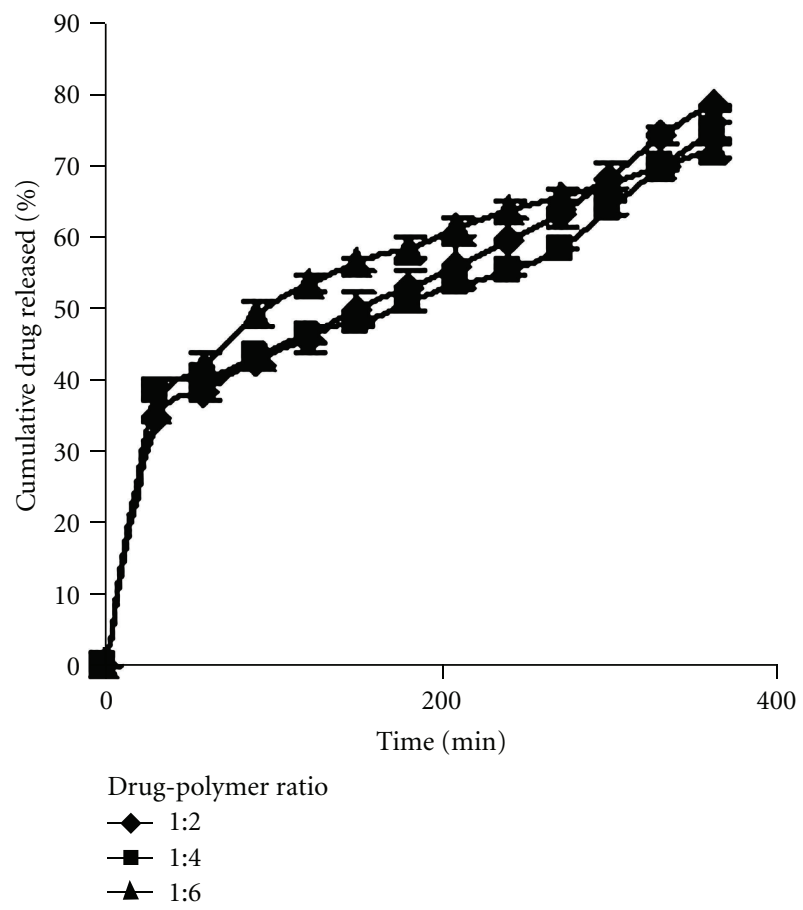

FIGURE 3: Effect of different drug-polymer ratio $(1: 2,1: 4$, and $1: 6)$ on the drug release in phosphate buffer, $\mathrm{pH} 6.8$.

elicit pharmacological activity. The effect of retardation on drug release rate depends on the drug-polymer ratio (Figures 3 and 4). As the ethyl cellulose content in the microparticles increased, the drug release rate from these microparticles was decreased. This may be attributed to the slower rate of drug diffusion from these microparticles into the dissolution mediums due to increased thickness of the polymeric matrix. On the other hand, the drug release from these microparticles was faster with the higher rate of stirring speed during their preparation (Figures 5 and 6 ). This could occurr due to the reduction of mean particle size of these ethyl cellulose microparticles with the higher stirring speed. The reduction of mean particle size of microparticles could facilitate higher rate of drug diffusion from larger surface area provided by

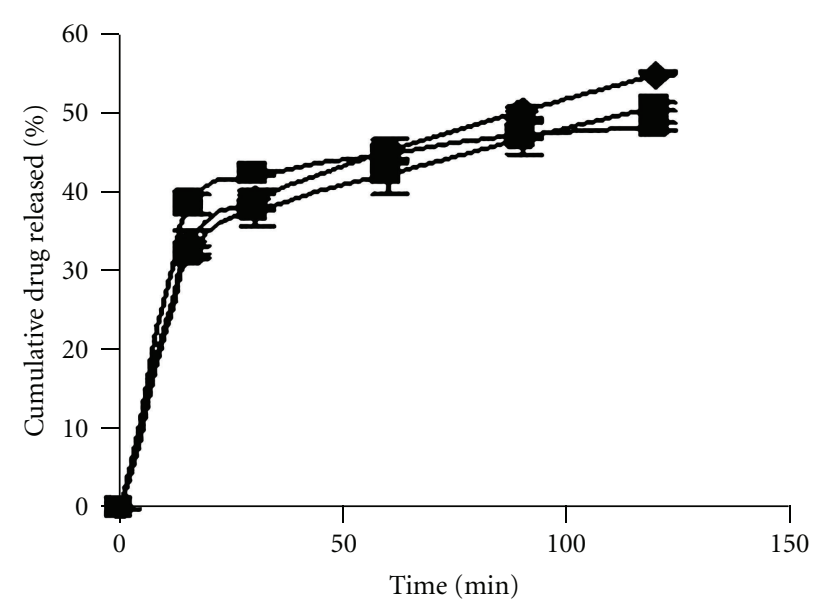

Drug-poly
$-1: 2$
$-1: 4$
$-1: 6$

FIGURE 4: Effect of different drug-polymer ratio $(1: 2,1: 4$, and $1: 6)$ on the drug release in $0.1 \mathrm{~N} \mathrm{HCl}, \mathrm{pH} 1.2$.

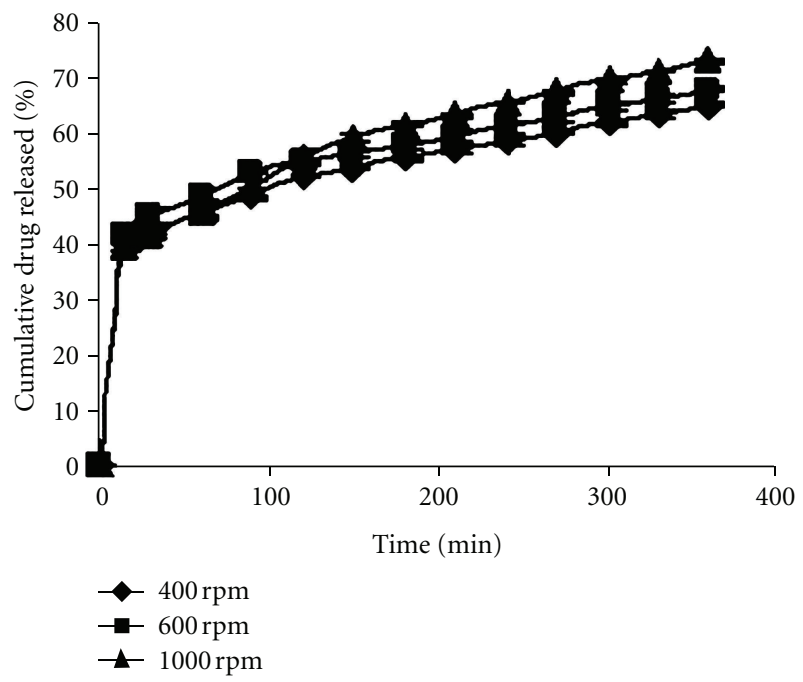

FIGURE 5: Effect of stirring speed (400, 600, and $1000 \mathrm{rpm})$ on the drug release in phosphate buffer, $\mathrm{pH} 6.8$.

the smaller microparticles. The release of drug from these microparticles also depends on the concentration of surfactant (Span 80), which was used at the time of preparation as stabilizer. As the concentration of Span 80 increased, the release rate was increased (Figures 7 and 8 ). This observation strongly supports the idea that the solubility enchantment of drugs by the effect of surfactant, Span 80 .

3.6. Release Kinetics. The determined values of $n$ (diffusional exponent) were varied within the range of 0.13 to 0.36 $\left(R^{2}=0.97\right.$ to 0.99$)$ for all the formulated ethyl cellulose microparticles containing metformin $\mathrm{HCl}$ (Table 3 ). The $n$ values indicated that the drug release from these microparticles prepared using different formulation variable settings 


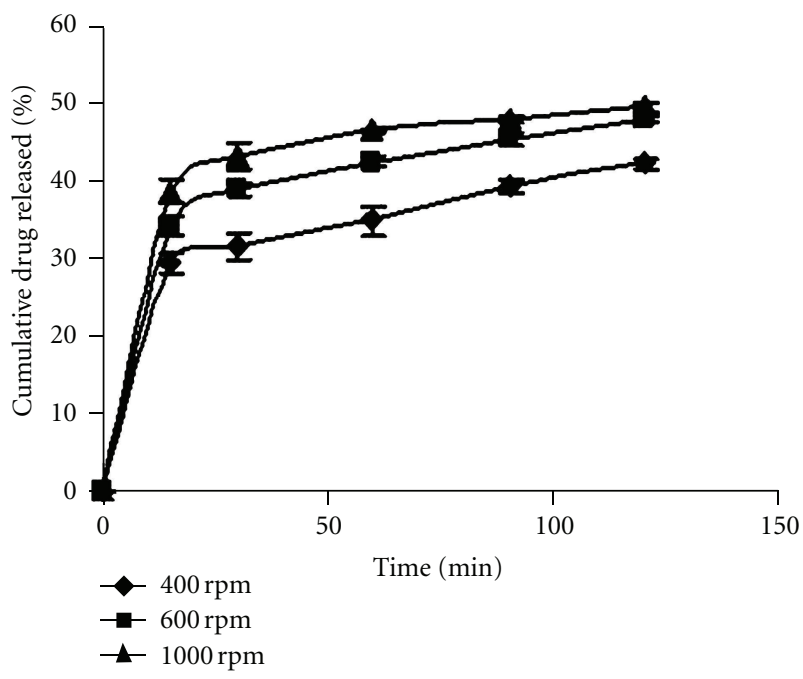

FIGURE 6: Effect of stirring speed (400, 600, and $1000 \mathrm{rpm})$ on the drug release in $0.1 \mathrm{~N} \mathrm{HCl}, \mathrm{pH} 1.2$.

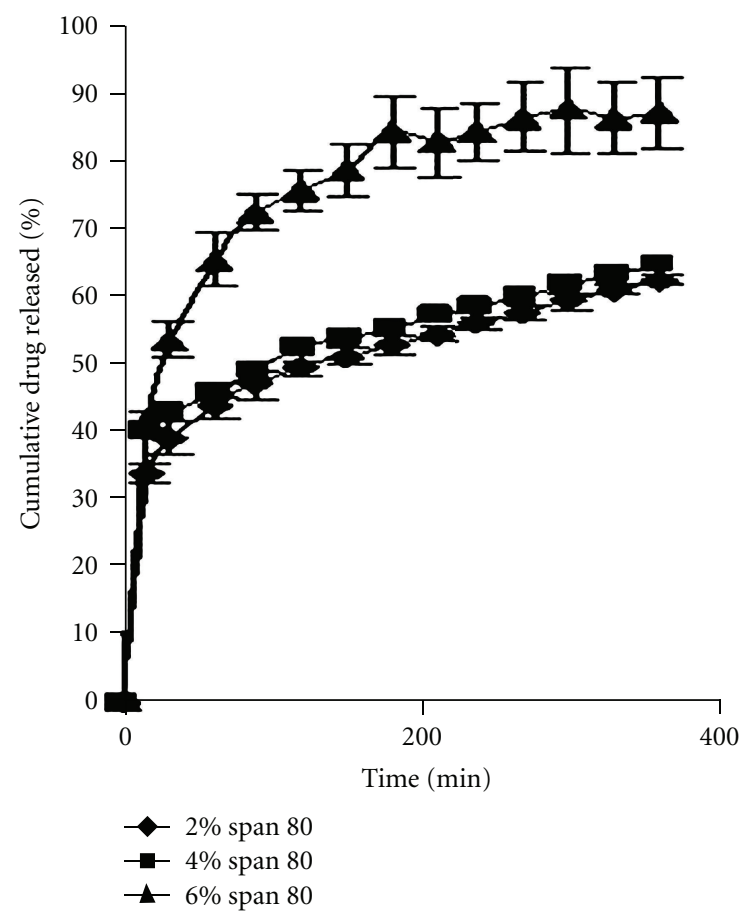

FIGURE 7: Effect of surfactant (Span 80) concentration (2, 4, and 6\% $\mathrm{v} / \mathrm{v}$ ) on the drug release in phosphate buffer, $\mathrm{pH} 6.8$.

followed the Fickian release or diffusion-controlled release mechanism $[20,21]$.

\section{Conclusion}

It can be concluded that the emulsification-solvent evaporation technique is a simple and reproducible method for the preparation of metformin $\mathrm{HCl}$-loaded ethyl cellulose microparticles. The drug entrapment efficiency, particle size, and drug release behaviour of these microparticles

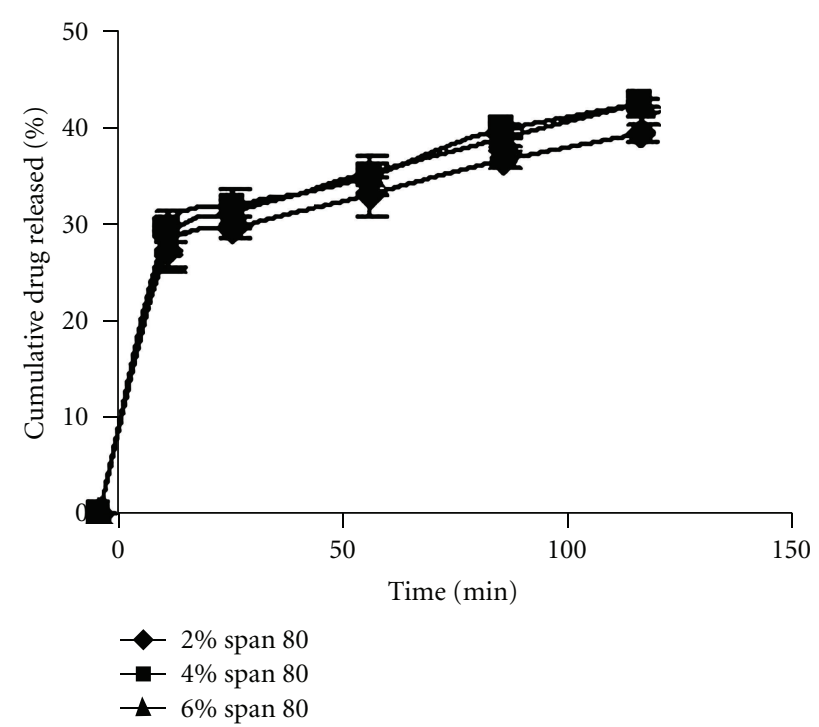

Figure 8: Effect of surfactant (Span 80) concentration (2, 4, and 6\% $\mathrm{v} / \mathrm{v}$ ) on the drug release in $0.1 \mathrm{~N} \mathrm{HCl}, \mathrm{pH} 1.2$.

TABLE 3: The $n$ values of different formulations.

\begin{tabular}{lc}
\hline Formulation codes & $n$ values* \\
\hline F1 & 0.26 \\
F2 & 0.20 \\
F3 & 0.29 \\
F4 & 0.14 \\
F5 & 0.13 \\
F6 & 0.17 \\
F7 & 0.18 \\
F8 & 0.36 \\
\hline
\end{tabular}

${ }^{*}$ The $n$ values for each microparticles were determined from logarithmic form of the power law equation: $\log \left[M_{t} / M_{\infty}\right]=\log k+n \log t$.

were influenced by various formulation variables like drugpolymer ratio, stirring speed, and surfactant (Span 80) concentration. Though the resulting microparticles discharged metformin $\mathrm{HCl}$ more rapidly in acidic $\mathrm{pH}$, than in alkaline $\mathrm{pH}$, sustained release was achieved in alkaline $\mathrm{pH}$. Once the release is reduced in acidic $\mathrm{pH}$ through modification, the ethyl cellulose microparticles can be useful for the delivery of highly water-soluble drug, metformin $\mathrm{HCl}$ in the management of noninsulin-dependent diabetes mellitus.

\section{References}

[1] D. Stepensky, M. Friedman, I. Raz, and A. Hoffman, "Pharmacokinetic-pharmacodynamic analysis of the glucose-lowering effect of metformin in diabetic rats reveals first-pass pharmacodynamic effect," Drug Metabolism and Disposition, vol. 30, no. 8, pp. 861-868, 2002.

[2] L. C. Block, L. O. Schemling, A. G. Couto, S. C. Mourão, and T. M.B. Bresolin, "Pharmaceutical equivalence of metformin tablets with various binders," Journal of Applied Pharmaceutical Science, vol. 29, no. 1, pp. 29-35, 2008. 
[3] V. K. Sharma and A. Bhattacharya, "Release of metformin hydrochloride from Ispaghula-sodium alginate beads adhered on cock intestinal mucosa," Indian Journal of Pharmaceutical Education and Research, vol. 42, no. 4, pp. 363-370, 2008.

[4] C. J. Dunn and D. H. Peters, "Metformin: a review of its pharmacological properties and therapeutic use in non-insulin-dependent diabetes mellitus," Drugs, vol. 49, no. 5, pp. 721-749, 1995.

[5] R. V. Kshirsagar, V. Jain, and S. Wattamwar, "Effect of different viscosity grade HPMC polymers on gastroretentive drug delivery of metformin $\mathrm{HCl}$," International Journal of Appllied Pharmaceutics, vol. 1, pp. 44-50, 2009.

[6] B. Nath, L. K. Nath, B. Mazumdar, N. K. Sharma, and M. K. Sarkar, "Preparation and in vitroevaluation of gastric floating microcapsules of metformin $\mathrm{HCl}$," Indian Journal of Pharmaceutical Education and Research, vol. 43, pp. 177-186, 2009.

[7] S. M. Setter, J. L. Iltz, J. Thams, and R. K. Campbell, "Metformin hydrochloride in the treatment of type 2 diabetes mellitus: a clinical review with a focus on dual therapy," Clinical Therapeutics, vol. 25, no. 12, pp. 2991-3026, 2003.

[8] S. Freiberg and X. X. Zhu, "Polymer microspheres for controlled drug release," International Journal of Pharmaceutics, vol. 282, no. 1-2, pp. 1-18, 2004.

[9] J. V. Desai, J. S. Patil, R. V. Kulkarni, S. C. Marapur, and V. V. Dalavi, "Alginate-based microparticulate oral drug delivery system for rifampicin," Research Journal of Pharmaceutical Technology, vol. 2, pp. 301-303, 2009.

[10] S. K. Basu and R. Adhiyaman, "Preparation and characterization of nitrndipine-loaded Eudragit RL 100 microspheres by an emulsion-solvent evaporation method," Tropical Journal of Pharmaceutical Research, vol. 7, pp. 1033-1041, 2008.

[11] S. P. Vyas and R. K. Khar, Targeted and Controlled Drug Delivery Novel Carrier Systems, CBS Publishers, New Delhi, India, 1st edition, 2002.

[12] A. Wade and P. J. Weller, Handbook of Pharmaceutical Excipients, The Pharmaceutical Press, Washington, DC, USA, 2nd edition, 1994.

[13] K. P. R. Chowdary, N. Koteswara Rao, and K. Malathi, "Ethyl cellulose microspheres of glipizide: characterization, in vitro and in vivo evaluation," Indian Journal of Pharmaceutical Sciences, vol. 66, no. 4, pp. 412-416, 2004.

[14] S. K. Sahoo, A. A. Mallick, B. B. Barik, and P. C. Senapati, "Preparation and in vitro evaluation of ethyl cellulose microspheres containing stavudine by the double emulsion method," Pharmazie, vol. 62, no. 2, pp. 117-121, 2007.

[15] P. C. Wu, Y. B. Huang, J. I. Chang, M. J. Tsai, and Y. H. Tsai, "Preparation and evaluation of sustained release microspheres of potassium chloride prepared with ethylcellulose," International Journal of Pharmaceutics, vol. 260, no. 1, pp. 115-121, 2003.

[16] M. Kar and P. K. Choudhury, "Formulation and evaluation of ethyl cellulose microspheres prepared by the multiple emulsion technique," Pharmazie, vol. 62, no. 2, pp. 122-125, 2007.

[17] P. Choudhury and M. Kar, "Controlled release metformin hydrochloride microspheres of ethyl cellulose prepared by different methods and study on the polymer affected parameters," Journal of Microencapsulation, vol. 26, no. 1, pp. 46-53, 2009.

[18] A. Patel, S. Ray, and R. S. Thakur, "Invitro evaluation and optimization of controlled release Floating Drug Delivery System of metformin hydrochloride," DARU Journal of Pharmaceutical Sciences, vol. 14, no. 2, pp. 57-64, 2006.

[19] R. W. Korsmeyer, R. Gurny, E. Doelker, P. Buri, and N. A. Peppas, "Mechanisms of solute release from porous hydrophilic polymers," International Journal of Pharmaceutics, vol. 15, no. 1, pp. 25-35, 1983.

[20] N. A. Peppas, "Analysis of Fickian and non-Fickian drug release from polymers," Pharmaceutica Acta Helvetiae, vol. 60, no. 4, pp. 110-111, 1985.

[21] R. Blagoeva and A. Nedev, "Monolithic controlled delivery systems: part II. Basic mathematical models," Bioautomation, vol. 5, pp. 106-117, 2006.

[22] R. Dinarvand, S. Mirfattahi, and F. Atyabi, "Preparation, characterization and in vitro drug release of isosorbide dinitrate microspheres," Journal of Microencapsulation, vol. 19, no. 1, pp. 73-81, 2002.

[23] Q. Yang and G. Owusu-Ababio, "Biodegradable progesterone microsphere delivery system for osteoporosis therapy," Drug Development and Industrial Pharmacy, vol. 26, no. 1, pp. 6170, 2000.

[24] K. R. Rao, P. Senapati, and M. K. Das, "Formulation and in vitro evaluation of ethyl cellulose microspheres containing zidovudine," Journal of Microencapsulation, vol. 22, no. 8, pp. 863-876, 2005. 

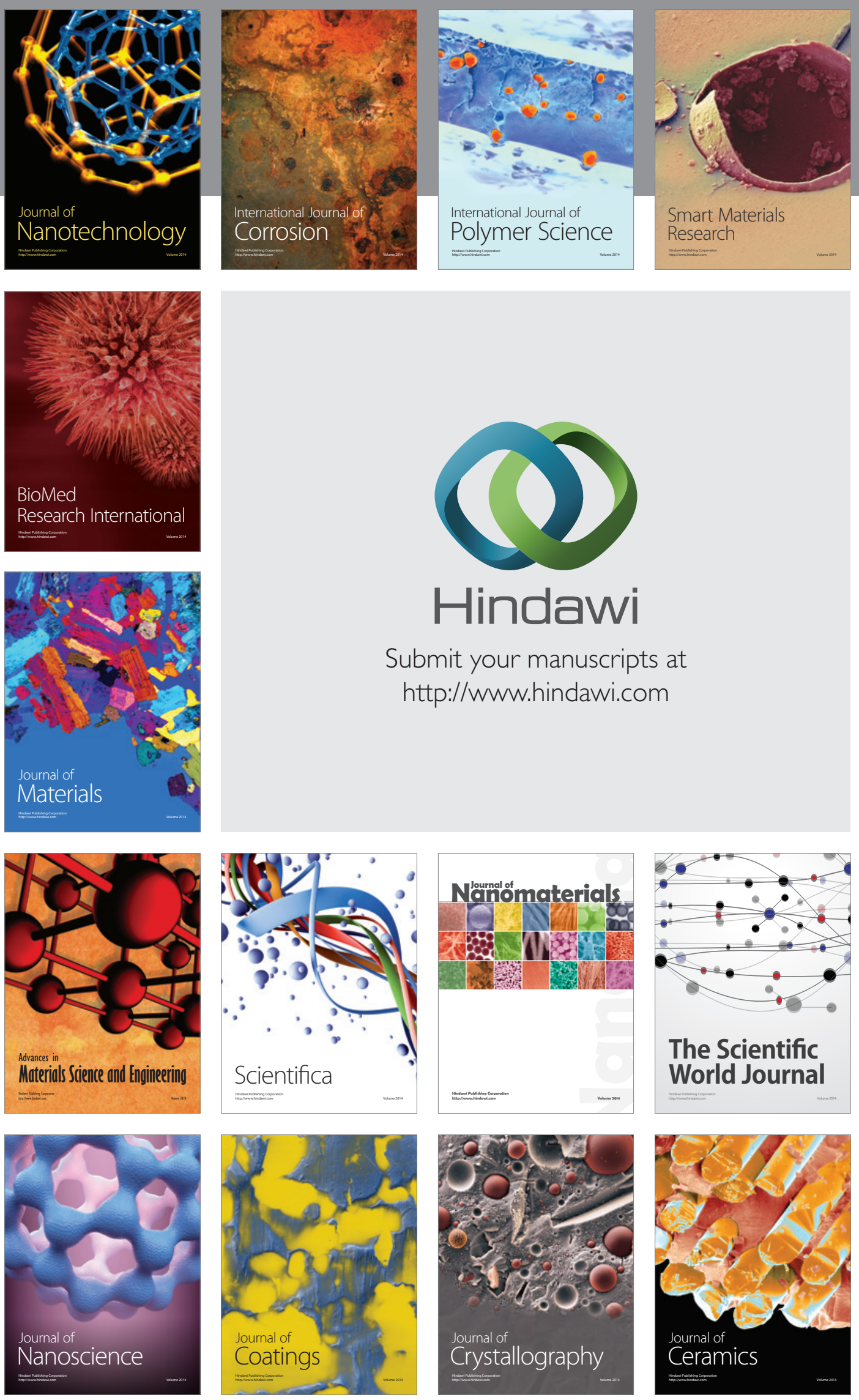

The Scientific World Journal

Submit your manuscripts at

http://www.hindawi.com

\section{World Journal}

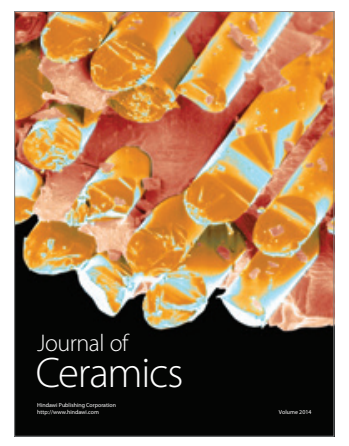

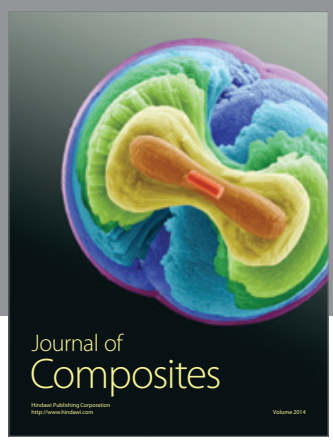
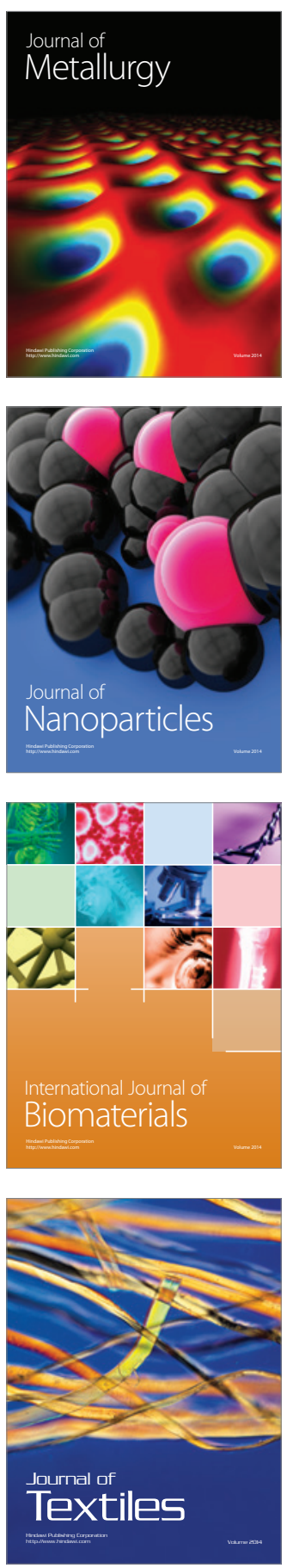